\title{
VALOR NUTRICIONAL DE ALIMENTOS PARA SUÍNOS DETERMINADO NA UNIVERSIDADE FEDERAL DE LAVRAS ${ }^{1}$
}

\author{
Nutritional value of feedstuffs for pigs determined at the university of Lavras
}

\author{
Zuleide Alves de Souza Santos ${ }^{2}$, Rilke Tadeu Fonseca de Freitas ${ }^{3}$, Elias Tadeu Fialho ${ }^{3}$, \\ Paulo Borges Rodrigues ${ }^{3}$, José Augusto de Freitas Lima ${ }^{3}$, Douglas de Carvalho Carellos ${ }^{4}$, \\ Patricia Azevedo Castelo Branco ${ }^{5}$, Vinicius de Souza Cantarelli ${ }^{5}$
}

\section{RESUMO}

Foram conduzidos seis ensaios de metabolismo no Departamento de Zootecnia da Universidade Federal de Lavras (UFLA) no ano de 2002, com objetivo de avaliar a composição química e nutricional de 8 alimentos protéicos e 10 energéticos. Para o primeiro ensaio, foram selecionados animais de peso-vivo médio de $40,4 \mathrm{~kg}$, sendo analisado o farelo de algodão, soja micronizada, farelo de soja, farelo de linhaça, farinha de pâncreas suíno, farinha de vísceras suína, milho comum, milheto em grão e moído, resíduo de bolacha, óleo de canola, óleo de linhaça, óleo de soja, gordura de coco e gordura suína. Para o segundo ensaio, foram selecionados animais de $50,2 \mathrm{~kg}$ e foi analisado o farelo de amendoim e milho QPM. Um total de 72 suínos machos, castrados e mestiços (Landrace x Large White), foram utilizados nos ensaios, e a metodologia adotada foi a da coleta total de fezes e urina. Desta forma, cada alimento foi testado em três repetições. Os valores obtidos de coeficiente de digestibilidade da proteína bruta (CDPB), valores de energia digestível (ED) e energia metabolizável (EM) para os alimentos protéicos de origem vegetal foram 66,2\%, $2480 \mathrm{kcal} / \mathrm{kg}, 2190 \mathrm{kcal} / \mathrm{kg}$, para farelo de algodão; 77,73\%, $2365 \mathrm{kcal} / \mathrm{kg}, 2289 \mathrm{kcal} / \mathrm{kg}$, para o farelo de girassol; 72,3\%, $2880 \mathrm{kcal} / \mathrm{kg}, 2580 \mathrm{kcal} / \mathrm{kg}$ para farelo de linhaça; 86,5\%, $3430 \mathrm{kcal}, 3360 \mathrm{kcal} / \mathrm{kg}$ para farelo de soja 46\% proteína bruta; 86,8\%, $4580 \mathrm{kcal} / \mathrm{kg}, 4350 \mathrm{kcal} / \mathrm{kg}$ para soja micronizada; 81,2\%, $3292 \mathrm{kcal} / \mathrm{kg}, 3146 \mathrm{kcal} / \mathrm{kg}$ para o farelo de amendoim. Para os alimentos protéicos de origem animal foram 47,3\%, $3470 \mathrm{kcal} / \mathrm{kg}, 3310 \mathrm{kcal} / \mathrm{kg}$ para farinha de pâncreas suína; 81,3\%, $3660 \mathrm{kcal} / \mathrm{kg}, 3535 \mathrm{kcal} / \mathrm{kg}$ para farinha de vísceras suína. Para os alimentos energéticos de origem vegetal foram 84,4\%, $3220 \mathrm{kcal} / \mathrm{kg}, 3185 \mathrm{kcal} / \mathrm{kg}$ para a farinha de bolacha; 85,3\%, $3480 \mathrm{kcal}, 3320 \mathrm{kcal} / \mathrm{kg}$ para o milho moído; 81,2\%, 3308 $\mathrm{kcal} / \mathrm{kg}$; $3257 \mathrm{kcal} / \mathrm{kg}$ para o milho QPM; 86,2\%, $3213 \mathrm{kcal} / \mathrm{kg}, 3048 \mathrm{kcal} / \mathrm{kg}$ para o milheto moído; 83,5\%, $3123 \mathrm{kcal} / \mathrm{kg}, 2950$ $\mathrm{kcal} / \mathrm{kg}$ para o milheto em grão inteiro. Para óleos e gorduras os valores de energia digestível (ED) e energia metabolizável (EM) foram $8630 \mathrm{kcal} / \mathrm{kg}, 8340 \mathrm{kcal} / \mathrm{kg}$ para o óleo de canola; $8380 \mathrm{kcal} / \mathrm{kg}, 8220 \mathrm{kcal} / \mathrm{kg}$ para o óleo de linhaça; $8670 \mathrm{kcal} / \mathrm{kg}$, $8340 \mathrm{kcal} / \mathrm{kg}$ para o óleo de soja; $8110 \mathrm{kcal} / \mathrm{kg}, 7960 \mathrm{kcal} / \mathrm{kg}$ para a gordura de coco; $8630 \mathrm{kcal} / \mathrm{kg}, 8280 \mathrm{kcal} / \mathrm{kg}$ para a gordura suína. De uma maneira geral, os dados analisados mostram variações na composição química, digestibilidade e valores energéticos dos alimentos, em relação aos citados nas tabelas brasileiras e estrangeiras, e valores citados por outras pesquisas referenciadas nas literaturas consultadas. Os valores obtidos no presente trabalho, além de fornecerem subsídios para aumentar as informações do banco de dados como forma de contribuir na elaboração de uma tabela nacional de alimentos para suínos, também poderão possibilitar melhorias técnicas para a formulação de rações para suínos.

Termos para indexação: Ingredientes, protéicos, energéticos, metabolismo.

\begin{abstract}
Six metabolism trials were conducted in the Animal Science Department at University of Lavras- (UFLA) with the objective to evaluate the chemical and nutritional composition of 8 protein and 10 energetic feeds utilized in swine rations. In the first metabolism assay, the pigs of means of $40.4 \mathrm{~kg}$ were utilized and the feeds cotton meal, micronized soybean, soybean meal, linseed meal, swine pancreas meal, swine viscera meal, common corn, ground and grain millet, backery residue, canola oil, linseed oil, soybean oil, coconut fat and swine fat were analyzed. In the second assa, the pigs with means of $50.2 \mathrm{~kg}$ were utilized and the feeds as peanuts meal and QPM corn were analyzed. All over the metabolism assays, a total of 72 barrows from crossbred (Landrace $\mathrm{x}$ Large White) were used, the methodology of the total collection of feces and urine were utilized. This way each feeds were tested in three replicates. The values of crude protein digestibility coefficient (CPDC), digestible energy (DE) and metabolizable energy (ME) for the proteic feeds from vegetal by-products were 66,2\%, $2480 \mathrm{Kcal} / \mathrm{kg}, 2190 \mathrm{Kcal} / \mathrm{kg}$ for cottonseed meal; 77,3\%, $2365 \mathrm{Kcal} / \mathrm{kg}, 2289 \mathrm{Kcal} / \mathrm{kg}$ for sun flower meal; 72,3\%, $2880 \mathrm{Kcal} / \mathrm{kg}, 2580 \mathrm{Kcal} / \mathrm{kg}$ for linseed meal; $86,5 \%, 3430 \mathrm{Kcal} / \mathrm{kg}$., $3360 \mathrm{Kcal} / \mathrm{kg}$ for soybean meal $46 \%$ of crude protein; 86,8.8\%, $4580 \mathrm{Kcal} / \mathrm{kg}, 4359 \mathrm{Kcal} / \mathrm{kg}$ for micronized soybean; 81,2\% $3292 \mathrm{Kcal} / \mathrm{kg}, 3146 \mathrm{Kcal} / \mathrm{kg}$ for peanuts meal. For the protein feeds from animal by-products were 47,3\%, $3470 \mathrm{Kcal} / \mathrm{kg}, 3310 \mathrm{Kcal} / \mathrm{kg}$ for swine pancreas meal; 81,3\%, $3660 \mathrm{Kcal} / \mathrm{kg}, 3550 \mathrm{Kcal} / \mathrm{kg}$ for swine viscera meal.

1. Parte da Dissertação apresentada à Universidade Federal de Lavras/UFLA - Caixa Postal 3037 - 37.200-000 - Lavras, MG - pela primeira autora.

2. Pesquisadora da EPAMIG, Médica Veterinária, MSc em Produção Animal.

3. Professor da Universidade Federal de Lavra/UFLA.

4. Professor da Escola Agrotécnica Federal de São João Evangelista.

5. Zootecnista, MSc em Nutrição Animal.
\end{abstract}


For the energetic feed from vegetal by-product were 84,4\%, $3220 \mathrm{Kcal} / \mathrm{kg}, 3185 \mathrm{Kcal} / \mathrm{kg}$ for biscuit meal; 85,3\%, 3480 $\mathrm{Kcal} / \mathrm{kg}, 3320 \mathrm{Kcal} / \mathrm{kg}$ for ground corn; 81.2\%, $3308 \mathrm{Kcal} / \mathrm{kg} ; 3257 \mathrm{Kcal} / \mathrm{kg}$ for QPM corn; 86.2\%, $3213 \mathrm{Kcal} / \mathrm{kg}, 3048$ $\mathrm{Kcal} / \mathrm{kg}$ for ground millet; 83.5\%, $3123 \mathrm{Kcal} / \mathrm{kg}, 2950 \mathrm{Kcal} / \mathrm{kg}$ for whole grain millet. For both oils and fats, the values of digestible energy (DE) and metabolizable energy (ME) were $8630 \mathrm{Kcal} / \mathrm{kg}, 8340 \mathrm{Kcal} / \mathrm{kg}$ for canola oil; $8380 \mathrm{Kcal} / \mathrm{kg}$, $8220 \mathrm{Kcal} / \mathrm{kg}$ for linseed oil; $8670 \mathrm{Kcal} / \mathrm{kg}, 8340 \mathrm{Kcal} / \mathrm{kg}$ for soybean oil $8110 \mathrm{Kcal} / \mathrm{kg}$, $7960 \mathrm{Kcal} / \mathrm{kg}$ for coconut fat; $8360 \mathrm{Kcal} / \mathrm{kg}, 8280 \mathrm{Kcal} / \mathrm{kg}$ for swine fat. In general, the data analyzed shown variations in the chemical composition, digestibility and energetic values of the feeds relative to those cited in the Brazilian and foreign tables and values reported by other researchers. The value obtained, in addition to furnishing subsides to increase information for data bank relative to the making of table for national swine feed table also will be able to contribute to tecnal improvement in formulating swine rations.

Index terms: protein, energetic feedstuffs, metabolism

\section{(Recebido para publicação em 28 de abril de 2003 e aprovado em 30 de novembro de 2004)}

\section{INTRODUÇÃO}

A constante preocupação em melhorar a produtividade e reduzir os custos com alimentação, tem levado nutricionistas a pesquisas, visando aprimorar o conhecimento sobre as características dos alimentos e suas limitações físicas ou químicas, para que possam ser utilizados adequadamente nas formulações de rações para suínos.

A formulação de rações que atendam as exigências nutricionais dos suínos modernos, depende do melhor conhecimento sobre a composição química dos ingredientes, bem como dos valores de digestibilidade e disponibilidade dos nutrientes, para se obter um máximo desempenho econômico desses animais. A tecnologia de formulação de rações, tanto nas indústrias quanto nas instituições de pesquisa é baseada em tabelas de composição de alimento e de exigências nutricionais brasileiras e estrangeiras. No entanto, em função de condições climáticas, espécie e variedade de grãos, origem, armazenamento e processamento a que os ingredientes são submetidos, a utilização de tabelas estrangeiras não seria recomendado. Dados das tabelas estrangeiras mostram-se diferentes, tanto na composição química quanto nos valores energéticos, dos referenciados na literatura nacional. Estas divergências apontaram para a necessidade de realização de ensaios de metabolismo e elaboração de tabelas de composição química e valores energéticos de alimentos produzidos e utilizados no Brasil.

A partir da década de 80, pesquisadores brasileiros intensificaram esforços para publicações de tabelas nacionais com a composição de alimentos para aves e suínos, sendo as mesmas periodicamente atualizadas e reeditadas (EMBRAPA, 1991). Estas tabelas são consideradas fontes de dados com o maior detalhamento nas informações de composição e valores nutricionais de alimentos mais comumente utilizados para suínos e aves no Brasil.

Albino (1991), comparando a composição química e níveis energéticos de diversos alimentos, observou uma grande variação nos valores inerentes aos subprodutos de origem animal e, segundo o autor, as variações ocorrem devido aos diferentes métodos de processamento e pela falta de padronização dos produtos nacionais.

Baier et al. (2000), estudando a influência do ambiente sobre os teores de proteína bruta e óleo em diferentes genótipos de triticale plantados no Rio Grande do Sul e Santa Catarina, concluíram que o ambiente (anos e locais), mais que os genótipos, afetaram a produtividade e a concentração de nutrientes nos grãos, que se relacionou negativamente com a produtividade. Num trabalho testando híbridos comerciais de milho, coletado em diferentes propriedades do Rio Grande Sul, na safra de 1998 e 1999, Lima (2000) observou uma grande variabilidade no teor de proteína bruta, dentro da mesma variedade (AG122: 6,84 - 11,95\%; AG9014: 7,48 - 12,33\%; P3063: 6,92 - 10,98\%; Premium: 7,51 $10,96 \%$ ) e que esta variabilidade não se repetiu quando considerou os aminoácidos lisina (0,25- 0,28\%; 0,26 $0,28 \%$; $0,27-0,28 \% ; 0,26-0,27 \%$, respectivamente) e metionina (0,28 - 0,31\%; 0,27 - 0,29\%; 0,27 - 0,29\%; $0,26-0,30 \%$, respectivamente), concluindo com estes resultados que o aumento no teor de proteína bruta pode ser devido a um aumento de nitrogênio não protéico proveniente da adubação nitrogenada.

As variações nos valores de composição química dos alimentos são sempre esperadas, uma vez que, variedades melhoradas geneticamente estão sempre sendo apresentadas ao mercado. Além das variações provenientes dos ingredientes, as várias técnicas de processamento originam subprodutos com uma composição química bastante variada. 
A diversidade de alimentos e seus subprodutos utilizados na formulação de rações são indicativos da necessidade de se conhecer, cada vez mais, os seus valores nutritivos e energéticos, objetivando melhor aproveitamento e utilização de forma mais racional, sendo que a precisão dos valores de composição química, energética e digestibilidade de nutrientes, além de necessária, são primordiais na busca da redução dos custos e de uma melhor produtividade (AZEVEDO, 1996).

A energia é o produto gerado pela transformação dos nutrientes da dieta. O aproveitamento da energia bruta contida no alimento depende de fatores ligados ao alimento, como, por exemplo, o teor de fibra presente e método de processamento; o nível de ingestão do alimento pelo animal e de seu peso e idade. Segundo Noblet e Peres (1993), para suínos em crescimento, o coeficiente de digestibilidade da energia diminui quando o nível de alimentação é elevado.

Com relação à fibra, os suínos digerem melhor a hemicelulose que a celulose, mas é o grau de lignificação que exerce a maior influência sobre a digestibilidade da fibra. A fibra pode afetar negativamente a utilização de alguns nutrientes, com conseqüente redução da digestibilidade da matéria seca, do extrato etéreo e da proteína bruta por aumentar a velocidade de passagem do alimento pelo trato gastrointestinal do suíno (KASS et al., 1980).

Quanto à influência do peso e idade dos animais sobre a digestibilidade dos alimentos, Fialho et al. (1979), trabalhando com diferentes alimentos para suínos com baixos teores de fibra bruta, não verificaram efeito da idade sobre os valores de energia digestível. Entretanto, observaram melhores coeficientes de digestibilidade da matéria seca e da proteína em animais mais velhos e ou pesados.

O processamento é outro fator que pode influenciar a digestibilidade dos alimentos. Este quando adequado, melhora a digestibilidade dos nutrientes de uma maneira geral e eleva o valor de energia metabolizável. O tratamento térmico normalmente favorece a digestibilidade dos nutrientes, em especial os aminoácidos e os lipídeos. O superaquecimento, por outro lado, pode levar à desnaturação de proteínas, oxidação do enxofre dos aminoácidos sulfurados, e à reação da lisina com grupos aldeído (reação de Maillard), formando um complexo indisponível, reduzindo a energia metabolizável (Penz JÚNIOR e Brugali, 2001).

Assim, este trabalho teve como objetivo avaliar a composição química e valores de digestibilidade de alimentos protéicos e energéticos mediante ensaios de me- tabolismo, realizados no setor de suinocultura do Departamento de Zootecnia da UFLA, no ano de 2002.

\section{MATERIAL E MÉTODOS}

Foram realizados dois ensaios metabólicos com suínos em fase de crescimento no Departamento de Zootecnia da UFLA, durante o ano de 2002. Foram avaliados 8 alimentos protéicos e 10 energéticos utilizados para alimentação de suínos.

Os alimentos protéicos avaliados foram o farelo de algodão, farelo de soja, farelo de girassol, soja micronizada, farelo de linhaça, farinha de pâncreas suíno, farinha de vísceras suína e farelo de amendoim. Os alimentos energéticos avaliados foram o milho comum, milho QPM, milheto moído e em grão, farinha de bolacha, óleo de canola, óleo de linhaça, óleo de soja, gordura de coco e gordura suína.

Nestes ensaios foram utilizados suínos mestiços (Landrace - LD x Large White - LW), machos, castrados. Para o primeiro ensaio, foram selecionados animais de peso-vivo médio de 40,4 kg e para o segundo, animais de 50,2 a 61,6 kg, distribuídos individualmente em gaiolas de metabolismo. Cada ensaio foi constituído por dois períodos experimentais, e cada período teve duração de 12 dias, sendo 7 dias de adaptação dos animais às gaiolas e às rações experimentais, e cinco dias para coleta total de fezes e urina.

A ração referência nestes ensaios foi à base de milho e farelo de soja, atendendo as exigências nutricionais dos animais. As rações teste continham $70 \%$ da ração referência e 30\% do alimento teste, em base de matéria seca, quando utilizou-se alimento protéico de origem vegetal, e animal e também energéticos de origem vegetal. Quando se utilizou óleos e gorduras, a ração teste continha $85 \%$ da ração referência e $15 \%$ do alimento teste. As rações foram fornecidas em duas refeições diárias, de acordo com a unidade de peso metabólico de cada animal. Cada alimento foi avaliado em 3 repetições, sendo a gaiola metabólica utilizada como unidade experimental.

A metodologia utilizada foi a de coleta total de fezes, empregando óxido férrico como marcador fecal, a fim de determinar o início e final do período de coleta de fezes e urina, de acordo com Fialho et al. (1979).

A composição química dos ingredientes, das rações, das fezes e da urina foi analisada no Laboratório de Nutrição Animal do Departamento de Zootecnia da UFLA, de acordo com a metodologia descrita pela AOAC (1990). Os valores de matéria seca digestível 
(MSD), coeficiente de digestibilidade da proteína bruta (CDPB), energia digestível (ED) e energia metabolizável (EM), foram determinados de acordo com as fórmulas de Matterson et al. (1965).

\section{RESULTADOS E DISCUSSÃO}

Observaram-se variações nos valores de composição química dos alimentos analisados (Tabela 1), em relação aos encontrados nas literaturas consultadas (EMBRAPA, 1991; NRC, 1998; FIALHO e BARBOSA, 2001; DALE, 2001). As maiores variações foram verificadas nos teores de proteína bruta (PB) do milho QPM (superior ao citado por Fialho e Barbosa (2001)), farelo de algodão (inferior ao referenciado pela EMBRAPA (1991) e superior a Dale (2001)), farelo de linhaça (superior ao citado pela EMBRAPA (1991)), farinha de vísceras suína (inferior aos valores citados pela EMBRAPA (1991)) e farelo de girassol (inferior ao citado por Dale (2001)). Essas variações podem estar ligadas ao método de obtenção e origem destes ingredientes.

Contataram-se também, nos alimentos analisados, variações nos valores energéticos e de digestibilidade dos nutrientes (Tabela 2), quando comparados aos citados nas literaturas brasileiras e estrangeiras, podendo estas variações estarem relacionadas ao processamento a que estes alimentos foram submetidos ou ao teor de fibra presente. A farinha de pâncreas suína apresentou o menor CDPB (47,3 \% na MN), este baixo valor de digestibilidade da proteína pode estar associado à altas temperaturas utilizadas no processamento de alguns subprodutos de origem animal, como observado por Morris e Ballouin (1972), que estudaram o efeito nutricional do processamento da farinha de penas hidrolisada.

TABELA 1 - Valores médios da composição química dos alimentos para suínos.

\begin{tabular}{|c|c|c|c|c|c|}
\hline Alimento & MS (\%) & PB (\%) & FDN(\%) ${ }^{1}$ & $\operatorname{FDA}(\%)^{1}$ & EB (Kcal/kg) ${ }^{1}$ \\
\hline Farelo de algodão & 89,1 & 32,1 & 28,4 & 17,4 & 4090 \\
\hline Farelo de girassol & 92,7 & 27,5 & 43,5 & 32,6 & 4390 \\
\hline Farelo de linhaça & 88,7 & 32,2 & 47,8 & 25,3 & 3980 \\
\hline Farelo de soja & 88,6 & 46,3 & 13,4 & 9,6 & 4178 \\
\hline Soja micronizada & 89,3 & 37,1 & 9,6 & 10,1 & - \\
\hline Farelo de amendoim & 92,7 & 49,6 & 11,54 & 9,7 & 4220 \\
\hline Farinha pâncreas suína & 91,8 & 56,5 & - & - & 4230 \\
\hline Farinha vísceras suína & 93,4 & 53,2 & - & - & 4189 \\
\hline Farinha de bolacha & 89,3 & 8,2 & - & - & 4350 \\
\hline Milho comum & 87,6 & 8,2 & 9,8 & 3,8 & 3980 \\
\hline Milho QPM & 89,9 & 10,1 & 11,2 & 3,4 & 4031 \\
\hline Milheto moído & 87,0 & 11,6 & 20,7 & 11,7 & 3980 \\
\hline Milheto grão & 87,2 & 11,3 & 20,9 & 12,1 & 4010 \\
\hline Óleo de canola & 99,4 & - & - & - & 9780 \\
\hline Óleo de linhaça & 99,3 & - & - & - & 9560 \\
\hline Óleo de soja & 99,2 & - & - & - & 9870 \\
\hline Gordura de сосо & 98,9 & - & - & - & 9780 \\
\hline Gordura suína & 99,3 & - & - & - & 9585 \\
\hline
\end{tabular}

${ }^{1}$ Valores expressos na base de matéria natural. MS: matéria seca; PB: proteína bruta; FDN: fibra em detergente neutro; FDA: fibra em detergente ácido; EB: energia bruta. 
TABELA 2 - Valores médios da matéria seca digestível (MSD), do coeficiente de digestibilidade da proteína bruta (CDPB), energia digestível (ED) e energia metabolizável (EM) dos alimentos para suínos.

\begin{tabular}{lcccc}
\hline \multicolumn{1}{c}{ Alimento } & MSD (\%) & CDPB (\%) & ED(Kcal/kg) & EM(Kcal/Kg) \\
\hline Farelo de algodão & $65,3 \pm 2,1$ & $66,2 \pm 2,3$ & $2480 \pm 40$ & $2190 \pm 47$ \\
Farelo de girassol & $54,4 \pm 1,1$ & $77,7 \pm 1,7$ & $2365 \pm 55$ & $2289 \pm 53$ \\
Farelo de linhaça & $75,3 \pm 2,4$ & $72,3 \pm 3,2$ & $2880 \pm 86$ & $2580 \pm 78$ \\
Farelo de soja & $87,1 \pm 2,7$ & $86,5 \pm 2,1$ & $3430 \pm 56$ & $3360 \pm 49$ \\
Soja micronizada & $85,3 \pm 1,5$ & $86,8 \pm 2,3$ & $4580 \pm 43$ & $4350 \pm 56$ \\
Farelo de amendoim & $75,8 \pm 1,2$ & $81,2 \pm 3,7$ & $3292 \pm 6,1$ & $3146 \pm 21$ \\
Farinha pâncreas suína & $58,2 \pm 3,1$ & $47,3 \pm 3,1$ & $3470 \pm 52$ & $3310 \pm 64$ \\
Farinha vísceras suína & $84,7 \pm 2,4$ & $81,3 \pm 1,4$ & $3660 \pm 48$ & $3535 \pm 56$ \\
Farinha de bolacha & $89,7 \pm 2,2$ & $84,4 \pm 2,5$ & $3220 \pm 76$ & $3185 \pm 69$ \\
Milho comum & $86,0 \pm 2,3$ & $85,3 \pm 1,2$ & $3480 \pm 65$ & $3320 \pm 59$ \\
Milho QPM & $82,5 \pm 0,5$ & $81,2 \pm 1,0$ & $3308 \pm 2,6$ & $3257 \pm 13$ \\
Milheto moído & $86,7 \pm 2,7$ & $86,2 \pm 1,6$ & $3213 \pm 42$ & $3048 \pm 52$ \\
Milheto grão & $86,3 \pm 2,1$ & $83,5 \pm 2,1$ & $3123 \pm 54$ & $2950 \pm 65$ \\
Óleo de canola & - & - & $8630 \pm 42$ & $8340 \pm 38$ \\
Óleo de linhaça & - & - & $8380 \pm 14$ & $8220 \pm 46$ \\
Óleo de soja & - & - & $8670 \pm 62$ & $8340 \pm 56$ \\
Gordura de coco & - & - & $8630 \pm 67$ & $7960 \pm 82$ \\
Gordura suína & - & - & $8280 \pm 74$ \\
\hline
\end{tabular}

${ }^{1}$ Valores expressos na base de matéria natural, seguidos dos respectivos erros-padrão da média.

Com relação ao CDPB dos ingredientes de origem vegetal, foi constatado que o farelo de algodão, o farelo de linhaça e o farelo de girassol, apresentaram os menores valores (66,2\%, 72,3\% e 77,7\%, respectivamente), assim como os menores valores de ED (2480, 2880 e 2365 $\mathrm{Kcal} / \mathrm{kg}$, respectivamente); e EM (2190, 2580 e 2289 $\mathrm{Kcal} / \mathrm{kg}$, respectivamente). Esses valores estão relacionados com o teor de fibra presente nestes ingredientes. A fibra pode afetar negativamente a utilização de alguns nutrientes, com conseqüente redução da digestibilidade da matéria seca, do extrato etéreo e da proteína bruta por aumentar a velocidade de passagem do alimento pelo trato gastrointestinal do suíno (KASS et al., 1980). Segundo Maust et al. (1972), a proteína não-digestível está protegida pela fibra dos alimentos que não foram digeridos e que esta pode estar associada à lignocelulose.
A energia digestível e metabolizável dos óleos e gorduras variam em função da origem, e essa variação está ligada ao número de insaturações dos ácidos graxos que os compõem. A gordura de coco foi a que apresentou menor aproveitamento da energia bruta (relação ED e EB de 82,9\%). Essa gordura é composta por apenas 8,5\% de ácidos graxos insaturados, o que pode ter levado a esta baixa relação. Os óleos de canola, de linhaça e de soja, apresentaram valores semelhantes na relação ED/EB (88,2\%, 87,6\% e 87,8\%, respectivamente). Estes resultados, possivelmente estão associados à presença de maior quantidade de ácidos graxos livres nestes óleos analisados, em função do processamento de obtenção.

Segundo Gaiotto (2000), algumas fontes têm como característica possuírem elevados níveis de ácidos graxos livres, e estes não ativam o processo de secreção

Ciênc. agrotec., Lavras, v. 29, n. 1, p. 232-237, jan./fev. 2005 
biliar e formação de micelas, conseqüentemente, não serão absorvidos pela mucosa intestinal.

\section{CONCLUSÕES}

A composição química dos alimentos analisados neste trabalho mostrou variações quando compradas entre si e entre os valores referenciados por outros pesquisadores brasileiros e estrangeiros.

O CDPB, ED e EM são influenciados pela fibra presente no alimento e pelo processamento a que este é submetido.

Os valores obtidos fornecem dados para confecção de tabela de alimentos nacionais, com o intuito de contribuir para melhoria da qualidade das rações para suínos.

\section{REFERÊNCIA BIBLIOGRAFICA}

ALBINO, L. F. T. Sistemas de avaliação nutricional de alimentos e suas aplicações na formulação de rações para frangos de corte. 1991. 141 f. Tese (Doutorado em Zootecnia) - Universidade Federal de Viçosa, Viçosa, 1991.

ASSOCIATION OF OFFICIAL ANALYTICAL CHEMISTY. Official methods of in Analysis. 15. ed. Arlington, 1990. 1230 p.

AZEVEDO, D. M. S. Fatores que afetam os valores de energia metabolizável da farinha de carne e ossos para aves 1996. 68 f. Dissertação (Mestrado) Universidade Federal de Viçosa, Viçosa, 1996.

BAIER, A. C. et al. Produtividade e concentração de nutrientes em triticale. In: REUNIÃO BRASILEIRA DE PESQUISA DE TRITICALE, 7., 2000, Guarapuava, PR. Anais... Guarapuava: [s.n.], 2000. p. 16-32.

DALE, N. Feedstuffs ingredient analysis table 2001. Feedstuffs, Athens, v. 73, n. 29, p. 28-29, july 2001.

EMPRESA BRASILEIRA DE PESQUISA AGROPECUÁRIA. Tabelas de composição química e valores energéticos de alimentos para suínos e aves. Brasília, 1997.

FIALHO, E. T.; BARBOSA, H. P. Alimentos alternativos para suínos. Lavras: FAEPE/UFLA, 2001. 196 p.
FIALHO, E. T.; ROSTAGNO, H. S.; FONSECA, J. B. Efeito do peso vivo sobre o balanço energético e protéico de rações a basede milho e sorgo com diferentes conteúdos de tanino para suínos. Revista da Sociedade Brasileira de Zootecnia, Viçosa, v. 8, n. 3, p. 396-397, 1979.

GAIOTTO, J. B. Óleo de soja, óleo ácido de soja e sebo bovino como fontes de gordura em rações para frangos de corte. 2000. Dissertação (Mestrado) - Escola Superior de Agricultura Luiz de Queiroz, Piracicaba, 2000.

KASS, M. L.; FOEST, P. J. van; POND, W. G. Utilization of dietary fiber from alfafa by growing swine: I. apparent digestibility of diet components in specific segments of gastrointestinal tract. Journal Animal Science, Champaign, v. 50, p. 175-191, 1980.

LIMA, G. J. M. M. Qualidade nutricional do milho: situação atual e perspectivas. In: SIMPÓSIO SOBRE MANEJO E NUTRIÇÃO DE AVES E SUÍNOS, 2000, Campinas, S.P. Anais... Campinas: CBNA, 2000. p. 153-174.

MATTERSON, L. D. et al. The metabolizable energy of feed ingredients for chickens. Storrs: University of Connecticut, 1965. $11 \mathrm{p}$.

MAUST, L. E. et al. The metabolizable energy of rice-bran, cassva flour and blackeye cowpeas for growing chiickers. Poultry Science, Champaign, v. 51, n. 4, p. 1397-1401, 1972.

MORRIS, W. C.; BALLOUIN, L. N. Effects de processing methods on the utilization of hidrolised feather meal broilers. Poutry Science, Champaign, v. 50, n. 5, p. 1609-1610, 1972.

NATIONAL RESEARCH COUNCIL. Nutrient requirements of swine. 9. ed. Washington, 1998.

NOBLET, J.; PERES, J. M. Prediction of digestibility of nutrients and energy values of pigs diets from chemical analysis. Journal Animal Science, Champaign, v. 71, n. 12, p. 3389-3398, 1993.

PENZ JUNIOR, A. M.; BRUGALI, I. Soja e seus derivados na alimentação de aves. In: SIMPÓSIO NACIONAL SOBRE INGREDIENTES NA ALIMENTAÇÃO ANIMAL, 2001, Campinas, S.P. Anais... Campinas: CBNA, 2001. p. 85-108. 
